\title{
Timeliness of Contraceptive Reinjections in South Africa And Its Relation to Unintentional Discontinuation
}

\author{
By Joy Noel \\ Baumgartner, \\ Chelsea Morroni, \\ Regina Dlakulu \\ Mlobeli, Conrad \\ Otterness, Landon \\ Myer, Barbara \\ Janowitz, John \\ Stanback and \\ Geoffrey Buga
}

Joy Noel Baumgartner is associate scientist, Health Services Research Division,

Family Health International (FHI),

Research Triangle Park, NC, USA;

Chelsea Morroni is senior researcher and Regina Dlakulu

Mlobeli is researcherboth with Women's Health Research Unit, School of Public

Health, University of Cape Town, Cape Town, South Africa; Conrad Otterness is research analyst, FHI; Landon Myer is senior lecturer, Infectious Disease Epidemiology Unit, School of Public

Health, University of Cape Town; Barbara

Janowitz is director and John Stanback is

scientist-both with

FHI; and Geoffrey

Buga is professor,

Department of

Obstetrics and

Gynaecology, Walter

Sisulu University,

Umtata, South Africa.

\begin{abstract}
CONTEXT: Research examining hormonal injectable contraceptive continuation has focused on clients' intentional discontinuation. Little attention, however, has been paid to unintentional discontinuation due to providers' management of clients who would like to continue use but arrive late for their scheduled reinjections.
\end{abstract}

METHODS: A cross-sectional survey of 1,042 continuing injectable clients at 10 public clinics was conducted in South Africa's Western and Eastern Cape provinces. Bivariate logistic regression analyses were used to identify associations between specific variables and the likelihood of receiving a reinjection, among clients who returned to clinics late but within the two-week grace period for reinjection.

RESULTS: Of 626 continuing clients in the Western Cape, 29\% were up to two weeks late and 25\% were 2-12 weeks late for their scheduled reinjection; these proportions among 416 continuing clients in the Eastern Cape were $42 \%$ and $16 \%$, respectively. Only $1 \%$ of continuing clients in the Western Cape who arrived during the two-week grace period did not receive a reinjection; however, $36 \%$ of similar clients in the Eastern Cape did not receive a reinjection. Among late clients in the Eastern Cape who did not receive a reinjection, 64\% did not receive any other method. Few variables were significant in bivariate analyses; however, certain characteristics were associated with receiving reinjections among late clients in the Eastern Cape.

CONCLUSIONS: It is common for clients to arrive late for reinjections in this setting. Providers should adhere to protocols for the reinjection grace period and have a contraceptive coverage plan for clients arriving past the grace period to reduce clients' risk of unintentional discontinuation and unintended pregnancy.

International Family Planning Perspectives, 2007, 33(2):66-74

Progestogen-only injectable contraceptives account for an increasingly large proportion of the mix of modern contraceptive methods used by women around the world, particularly in Sub-Saharan Africa. Although injectables such as depot medroxyprogesterone acetate (DMPA) and norethisterone enantate (NET-EN) are among the most efficacious methods available, their effectiveness in practice is reduced because their continuation rates are lower than those of other methods. ${ }^{1-4}$

To use an injectable method, clients must adhere to certain timing guidelines for the initial injection and for subsequent reinjections. Protocols to start DMPA or NET-EN use require a woman to receive the initial injection within seven days of the start of her menstrual bleeding or at any other time when it is reasonably certain that she is not pregnant. ${ }^{5}$ For a follow-up injection, the 2004 Selected Practice Recommendations for Contraceptive Use of the World Health Organization (WHO) state that a woman who is up to two weeks early or two weeks late is still eligible to receive a reinjection. ${ }^{5}$ Thus, women have a four-week inter-

*Other guidelines suggest that a reinjection may be appropriate in some circumstances for women returning up to four weeks late (source: U.S. Agency for International Development (USAID), MAQ Technical Guidance and Competence (TG/C) Subcommittee Recommendations for Updating Selected Practices in Contraceptive Use, Vols. I \& II, USAID, 1997). val (centered on three months after their last DMPA injection or two months after their last NET-EN injection) in which to receive their follow-up injection. *

The two weeks after the scheduled reinjection date have been called the "grace period" for reinjection. Clients who return after the grace period should undergo testing prior to reinjection to rule out pregnancy, because the effects of injectable use during pregnancy on the fetus remain unclear. ${ }^{6}$ In low-resource settings, the requirement for pregnancy testing may present a barrier to reinjection, because tests are not available or because the cost to clinics and clients is prohibitive. Clients who arrive past their scheduled follow-up injection date may be denied reinjection and asked to return during their next menses, to ensure that they are not pregnant. ${ }^{7}$ Besides being an unnecessary burden for women who may have trouble reaching clinics, the "with-menses" management approach for late clients is particularly problematic for women who may wait up to six months or longer for their menses to return due to the unpredictable physiological effects of injectables. ${ }^{8}$

Women seeking reinjection who are turned away may receive little or no counseling about interim contraceptive protection. Alternatively, they may receive counseling to use condoms or to abstain from sexual intercourse until they return to the clinic during their next menses; however, con- 
dom use and abstinence may be unacceptable or unrealistic for women or their partners. Requiring "with-menses" follow-up administration for late injectable clients may result in unmet contraceptive need, waning motivation for contraceptive continuation and unintended pregnancy.

In South Africa, hormonal contraceptives are available free of charge at all public sector clinics, and contraceptive use is high, with $61 \%$ of sexually active $15-49$-year-old women using a modern contraceptive method. ${ }^{9}$ Both the two-month (NET-EN) and the three-month (DMPA) injectables are widely offered throughout the country, and together account for $49 \%$ of current contraceptive use nationally and up to $90 \%$ in some settings. ${ }^{9-11}$ Despite widespread availability of family planning services and high contraceptive uptake, South African women still experience high rates of unintended pregnancy: An estimated 53\% of South African pregnancies are either unplanned (36\%) or unwanted (17\%). ${ }^{9}$

The 2003 South African Contraceptive Guidelines are aligned with the WHO contraceptive practice recommendations, except for two important aspects. First, WHO guidelines state that a woman should return for her reinjection after three months for DMPA or two months for NET-EN, whereas the South African guidelines (similar to other country-specific guidelines) state that reinjections are required every 12 weeks for DMPA and every eight weeks for NETEN. ${ }^{5,12,13}$ Second, the WHO recommendations permit a twoweek grace period for returning injectable users when pregnancy does not need to be ruled out to receive a reinjection; ${ }^{13}$ South African service delivery guidelines, however, are more lenient. If pregnancy cannot be ruled out for a continuing client who is more than two weeks late for a scheduled reinjection, and she is unable to use condoms or abstain, the guidelines say that an injection may be given "on the understanding that it will not abort or harm an existing pregnancy" and that a follow-up appointment should be scheduled in four weeks to check for pregnancy. ${ }^{13}$

Many studies on injectable contraceptive continuation have focused on or assumed intentional client discontinuation, often attributing it to side effects. Scant attention has been paid to unintentional discontinuation among women who wish to continue using the injectable, but who arrive late for their reinjections. This study assesses the extent to which lateness for hormonal contraceptive reinjections occurs among clients and whether being late for follow-up reinjections contributes to clients' contraceptive discontinuation.

\section{METHODS \\ Data Collection}

We conducted a cross-sectional study of new, restarting and continuing injectable contraceptive clients aged 15 years or older at primary-level public clinics in two South African provinces: the Western Cape and the Eastern Cape. The Western Cape has a fairly well developed health infrastructure, especially in the Cape Town area; the Eastern Cape is made up of two of South Africa's former African "home- lands" (the Transkei and the Ciskei) and is widely regarded as the province that is the poorest and has the least developed health infrastructure.

Five clinics in each province were selected by purposive stratified sampling to represent rural, periurban and urban client populations in each province. For the Western Cape, clients were interviewed at one urban clinic, one rural clinic and three periurban clinics located in townships on the outskirts of a large city; one of the periurban clinics served only clients aged 24 or younger. For the Eastern Cape, client interviews were conducted at two rural clinics, one periurban clinic and two clinics classified as urban although they were each located in a small- or medium-sized town. In each province, interviews were equally distributed among the rural, periurban and urban clinics. The local, provincial and national departments of health approved the study, and ethical approval was granted by Family Health International, the University of Cape Town and Walter Sisulu University (formerly University of Transkei).

Between February and July 2005, research assistants attempted to screen all family planning clients at the study clinics to determine whether they were there that day for a contraceptive injection. Those who were at the clinic to receive an injection were invited to be interviewed after their clinic visit; all respondents gave oral informed consent prior to participation.

During face-to-face interviews, respondents were asked about their social and demographic characteristics; the date of their first and last injection of DMPA or NET-EN; whether they considered themselves late for reinjection; if late, what reasons they had for not arriving on time; whether they had received an injection or another contraceptive method during their visit; how their case had been managed by the provider, including information given about timing for the next injection; and their future intentions in regard to injectable use. Interviews took approximately 30 minutes to complete. After obtaining clients' consent, we checked their family planning cards to confirm dates of last injection and of follow-up reinjection. * Among eligible clients, the refusal rate was 16\% in the Western Cape and 5\% in the Eastern Cape. Most women who refused to participate did so because they did not want to wait or because they did not have time.

\section{Outcomes}

For this study, clients who returned to the clinic early, on time or 1-84 days (a 12-week DMPA cycle) after their scheduled date for DMPA or NET-EN reinjection were classified as continuing clients. The purposefully broad classification of continuing clients presents a comprehensive picture of lateness that includes women arriving within and after the grace period, who may or may not have been intentionally late, but who want to continue using an injectable contraceptive. Clients who returned for a reinjection more than 12 weeks late were considered to be restarting clients;

* Most family planning clients have a family planning card, which includes their name, the dates of their past injections and, if they had received an injection the day of interview, the date for their next scheduled injection. 
TABLE 1. Selected characteristics of continuing injectable clients of 10 public clinics in Western Cape and Eastern Cape provinces, South Africa, 2005

\begin{tabular}{|c|c|c|}
\hline Characteristic & $\begin{array}{l}\text { Western } \\
\text { Cape }\end{array}$ & $\begin{array}{l}\text { Eastern } \\
\text { Cape }\end{array}$ \\
\hline All & $(\mathrm{N}=626)$ & $(\mathrm{N}=416)$ \\
\hline \multicolumn{3}{|l|}{ Injectable administered at last visit† } \\
\hline DMPA & 48 & 50 \\
\hline NET-EN & 52 & 50 \\
\hline \multicolumn{3}{|l|}{ Age } \\
\hline $15-19$ & 21 & 16 \\
\hline $20-29$ & 47 & 49 \\
\hline $30-39$ & 25 & 28 \\
\hline$\geq 40$ & 7 & 7 \\
\hline Primary language IsiXhosa & 73 & 98 \\
\hline$\geq 10$ yrs. education & 68 & 68 \\
\hline Unemployed & 37 & 42 \\
\hline No. of minutes to clinic (mean) & 22.5 & 34.7 \\
\hline \multicolumn{3}{|l|}{ Housing } \\
\hline House/permanent building & 51 & 38 \\
\hline Shack & 48 & 5 \\
\hline Traditional hut & 1 & 56 \\
\hline \multicolumn{3}{|l|}{ Relationship status } \\
\hline Married/cohabiting & 27 & 19 \\
\hline Married/not cohabiting & 3 & 7 \\
\hline Single/in relationship & 64 & 70 \\
\hline Single/no relationship & 5 & 2 \\
\hline No response & 1 & 1 \\
\hline Sexually experienced & $(\mathrm{N}=625)$ & $(\mathrm{N}=415)$ \\
\hline \multicolumn{3}{|l|}{ Time since last sex } \\
\hline$\leq 7$ days & 65 & 46 \\
\hline 8-14 days & 10 & 13 \\
\hline $15-30$ days & 3 & 5 \\
\hline $31-60$ days & 6 & 13 \\
\hline$>60$ days & 16 & 23 \\
\hline Used condom at last sex & 32 & 32 \\
\hline Ever pregnant & 73 & 83 \\
\hline Ever pregnant & $(\mathrm{N}=457)$ & $(\mathrm{N}=346)$ \\
\hline No. of children (mean) & 2.0 & 2.3 \\
\hline Last pregnancy mistimed/unwanted & 61 & 82 \\
\hline
\end{tabular}

those who mentioned having used an injectable at some time in the past were also considered restarting clients.

For $72 \%$ of continuing clients, we determined timeliness for reinjection by checking their family planning cards; for the $28 \%$ of continuing clients who did not bring a family planning card to their appointment, timeliness was determined by clients' self-report. A comparison by the source of information (client recall vs. family planning card) did not reveal any systematic bias or clustering.

The primary outcomes measured in this study were the proportion of continuing injectable clients who arrived late (after their scheduled date) for their reinjections; the proportion of late continuing injectable clients who left the clinic without receiving a reinjection; the characteristics of injectable clients who were late for their reinjections; and the factors related to the likelihood that clients who were late but within the grace period would receive a reinjection.

\section{Data Analysis}

We conducted bivariate analyses using simple logistic regression to identify associations between individual variables and being late for a scheduled reinjection; addition- al analyses were conducted to examine the likelihood of receiving a reinjection among clients who were late, but within the two-week grace period. The lateness variable was coded as dichotomous (early or on time vs. late) after preliminary analyses showed that the results remained unchanged, regardless of whether lateness was analyzed as continuous, dichotomous or polytmous (on time, late within grace period or late beyond grace period). For the analysis of clients who arrived late, data are presented in aggregate after preliminary analysis with bivariate logistic regression found no significant differences by province, location (urban, periurban or rural), or type of injectable. All analyses were conducted in SAS version 9.1

Analyses took into account clustering at the clinic level. There were 10 clinics (clusters), with an average of 104 clients per clinic (average cluster size). The number of clients in each clinic cluster ranged from 11 to 193 . The intracluster correlation coefficient (ICC) for a continuing client being late for their scheduled reinjection was calculated as 0.0489 .

\section{RESULTS Descriptive Analyses}

Overall, 819 injectable clients in the Western Cape and 684 clients in the Eastern Cape were interviewed. The proportion of new injectable clients was the same in both regions (15\%). Nine percent of clients in the Eastern Cape were restarting clients and $76 \%$ were continuing clients; the proportions for the Western Cape were 25\% and 61\%, respectively.

Among the 626 continuing injectable clients in the Western Cape, 48\% used DMPA and 52\% NET-EN (Table 1); these proportions among the 416 continuing clients in the Eastern Cape were each 50\%. Bivariate analyses indicated the only statistically significant difference in characteristics of users by type of injection was that NET-EN users were younger than DMPA users (mean age, 24.1 years vs. 29.9 years; $\mathrm{p}<.005-$ not shown). Forty-eight percent of continuing clients in the Western Cape reported having used both DMPA and NET-EN in the past; the proportion in the Eastern Cape was 35\%.

The majority of continuing clients in each province were younger than 30, spoke IsiXhosa as their first language and had 10 or more years of education (Table 1). Thirty-seven percent of clients in the Western Cape and 42\% in the Eastern Cape were unemployed. Twenty-seven percent of clients in the Western Cape and 19\% in the Eastern Cape were married and cohabiting

All but two continuing clients-one in each provincewere sexually experienced. Twenty-two percent of sexually experienced clients in the Western Cape and 36\% in the Eastern Cape reported not having had sex in the past 30 days, and $32 \%$ in each province reported using a condom at last sex. Seventy-three percent of sexually experienced clients in the Western Cape and 83\% in the Eastern Cape had ever been pregnant; among those, $61 \%$ and $82 \%$, respectively, reported that their last pregnancy had been mistimed or unwanted. 


\section{Timeliness Among Continuing Clients}

Of continuing clients in the Western Cape, 46\% were early or on time for their scheduled reinjection appointment, 29\% were up to two weeks late and 25\% were 2-12 weeks late (Figure 1); in the Eastern Cape, the proportions were 43\%, $42 \%$ and $16 \%$, respectively. Thirty-nine percent of continuing clients in both provinces described themselves as being late for their reinjection (not shown). Of those, more than 97\% reported that they had expected to receive an injection the day they arrived for services. Even among those who were more than two weeks late, $97 \%$ said they had expected to receive a reinjection.

Although South African contraceptive guidelines indicate that pregnancy tests should be used to rule out pregnancy for continuing clients arriving past the grace period, no clients in the Western Cape and only 10 in the Eastern Cape received a urine pregnancy test. Of the 10 clients who were given pregnancy tests, only one had come in after the grace period ( 40 days past her scheduled reinjection date); the other nine were either on time or no more than three days late.

- Clients' reasons for and beliefs about being late. Clients gave widely varied responses as to why they were late for their reinjection appointments. Among clients whom we classified as late and who also considered themselves as being late (Western Cape, N=241; Eastern Cape, N=179), 30\% mentioned conflicting priorities (e.g., inability to be absent from work or school, inconvenient clinic hours, no time on the scheduled date or family commitments) as their main reason for being late; 16\% forgot their appointment, 15\% lacked resources (transportation and money), 6\% were out of the area on the scheduled date, $4 \%$ were not sexually active at the time of their scheduled appointment, 3\% wanted to see their period or to take a break from the method, and $17 \%$ did not provide a response.

About $40 \%$ of continuing clients said the risk of pregnancy after missing a scheduled reinjection existed after two weeks or they gave a response along similar lines (i.e. until injection wears off, depends on length of injectable use, until menses returns). In other words, many clients believed that the injectable continued to provide protection for some time beyond the grace period. An additional 31\% did not know when they were at risk of pregnancy.

- Reinjection among late clients. Of the clients who presented within the two-week grace period, 36\% in the Eastern Cape did not receive a reinjection, whereas only about $1 \%$ of eligible Western Cape clients did not receive one (Table 2). There were no periods when the injectable was out of stock in either province during the course of the study that would account for different reinjection rates.

Among continuing clients in the Eastern Cape who were late and did not receive an injection, 64\% received no other method and $71 \%$ were told to return during menses (not shown). Of those who received another method, $75 \%$ received oral contraceptives, $64 \%$ received condoms and $7 \%$ received emergency contraception (some clients received more than one method).
FIGURE 1. Percentage distribution of clients wanting to continue injectable use, by when they arrived for their reinjection appointment

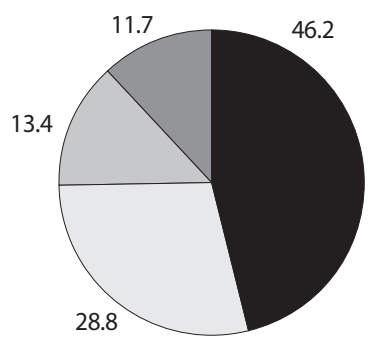

Western Cape $(\mathrm{N}=626)$

On time $\square$ 1-14 days late

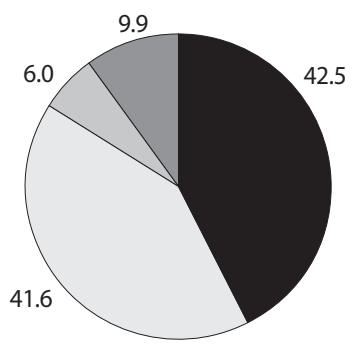

Eastern Cape $(\mathrm{N}=416)$
29-84 days late
Of the Eastern Cape clients who did not receive a reinjection (including seven women who were on time), $74 \%$ reported being told to return during their next menses; 14\% were given a specific date to return (in 1-3 months). When asked why they thought they did not receive a reinjection, $53 \%$ thought it was because they came in too late, $14 \%$ because they were not menstruating, $11 \%$ because they were too young or had not yet had a child and $8 \%$ because the side effects were not good for them; 14\% said they did not know. Clients' responses reflected what they had been told by providers, as well as their perceptions if the provider had not given an explanation.

Clients were given limited information by providers regarding the consequences of being late and what they should do if they could not make their next scheduled reinjection date. Eighty-five percent of continuing clients who received an injection the day of the interview said a specific date for reinjection had been given to them verbally or had been written on their family planning card, and 14\% said the provider had not told them when to return for reinjection. Of clients given a specific date, only $10 \%(\mathrm{~N}=80)$ were told what to do if they could not return on their scheduled date; of those, 21 said the provider indicated they could return earlier, 19 said they had been told they would get pregnant if they were late (without clarification on how late)

\begin{tabular}{|c|c|c|c|}
\hline Timeliness & Received & Did not receive & Total \\
\hline \multicolumn{4}{|l|}{ Western Cape } \\
\hline On timet & 99.7 & 0.3 & 100.0 \\
\hline 1-14 days late & 99.4 & 0.6 & 100.0 \\
\hline 15-28 days late & 97.6 & 2.4 & 100.0 \\
\hline 29-84 days late & 94.5 & 5.5 & 100.0 \\
\hline \multicolumn{4}{|l|}{ Eastern Cape } \\
\hline On timet & 96.1 & 3.9 & 100.0 \\
\hline 1-14 days late & 63.6 & 36.4 & 100.0 \\
\hline 15-28 days late & 4.0 & 96.0 & 100.0 \\
\hline 29-84 days late & 17.1 & 82.9 & 100.0 \\
\hline
\end{tabular}


TABLE 3. Unadjusted odds ratios from logistic regression analysis examining the likelihood that injectable users were late for reinjection, by selected characteristics

\begin{tabular}{|c|c|c|c|}
\hline Characteristic & Odds ratio & Characteristic & Odds ratio \\
\hline \multicolumn{2}{|l|}{ Area } & \multicolumn{2}{|l|}{ Last pregnancy was wanted } \\
\hline Western Cape (ref) & 1.00 & Then (ref) & 1.00 \\
\hline Eastern Cape & 1.16 & Later & 1.06 \\
\hline \multicolumn{2}{|l|}{ Type of injectable used prior to current clinic visit } & Never & 0.80 \\
\hline NET-EN (ref) & 1.00 & \multicolumn{2}{|l|}{ Client happy if pregnant in next 6 mos. } \\
\hline \multirow[t]{2}{*}{ DMPA } & 1.16 & No (ref) & 1.00 \\
\hline & & Yes & 1.20 \\
\hline \multicolumn{4}{|l|}{ Social and demographic } \\
\hline Age & & Service experience/quality of care & \\
\hline $15-19$ & 0.93 & Ever been late for scheduled reinjection & \\
\hline $20-29$ (ref) & 1.00 & No (ref) & 1.00 \\
\hline $30-39$ & 0.97 & Yes & $3.95^{* *}$ \\
\hline$\geq 40$ & 0.85 & Ever left clinic without method & \\
\hline \multicolumn{2}{|l|}{ Education } & No (ref) & 1.00 \\
\hline$\leq 9$ th grade (ref) & 1.00 & Yes & $1.85^{* *}$ \\
\hline$\geq 10$ th grade & 0.75 & Ever left clinic without injection & \\
\hline \multicolumn{2}{|l|}{ Occupation } & No (ref) & 1.00 \\
\hline Unemployed (ref) & 1.00 & Yes & $2.07^{* *}$ \\
\hline Employed & 0.84 & \multicolumn{2}{|c|}{ Ever told to return during menses (family planning visit) } \\
\hline Student/scholar & 0.93 & No (ref) & 1.00 \\
\hline Homemaker/government grant/pension/other & 1.17 & Yes & 1.09 \\
\hline \multicolumn{2}{|l|}{ Housing } & \multicolumn{2}{|l|}{ Ever told to return during menses (injection visit) } \\
\hline House (ref) & 1.00 & No (ref) & 1.00 \\
\hline Other & 1.02 & Yes & 1.09 \\
\hline \multicolumn{2}{|l|}{ Relationship status } & \multirow{2}{*}{\multicolumn{2}{|c|}{$\begin{array}{l}\text { Ever counseled on potential side effects/ } \\
\text { health problems of injectable }\end{array}$}} \\
\hline Married (ref) & 1.00 & & \\
\hline Single & 1.25 & Yes (ref) & 1.00 \\
\hline \multicolumn{2}{|l|}{ Partner knows client is using this method } & No & 1.02 \\
\hline Yes (ref) & 1.00 & \multirow{2}{*}{\multicolumn{2}{|c|}{$\begin{array}{l}\text { Perceived timing of pregnancy risk } \\
\text { after missing scheduled reinjection }\end{array}$}} \\
\hline No & 1.25 & & \\
\hline \multicolumn{2}{|l|}{ Partner approves client's injectable use } & $\leq 2$ wks (ref) & 1.00 \\
\hline Yes (ref) & 1.00 & $>2$ wks/other $\neq$ & 1.06 \\
\hline No & 0.96 & & \\
\hline No opinion & $1.68^{*}$ & \multicolumn{2}{|l|}{ Potential access barriers } \\
\hline \multicolumn{2}{|l|}{ Last sex was $>30$ days ago } & \multicolumn{2}{|l|}{ Transportation to clinic } \\
\hline \multirow{3}{*}{$\begin{array}{l}\text { No (ref) } \\
\text { Yes }\end{array}$} & 1.00 & Other (ref) & 1.00 \\
\hline & 1.33 & Walked & 1.24 \\
\hline & & No. of minutes to clinic (mean) & 0.99 \\
\hline \multicolumn{2}{|l|}{ Pregnancy history/intentions } & \multicolumn{2}{|l|}{ Missed school or work to visit clinic today } \\
\hline Ever pregnant & & No (ref) & 1.00 \\
\hline Yes (ref) & 1.00 & Yes & 1.03 \\
\hline No & 0.72 & \multicolumn{2}{|l|}{ Client's last injection was } \\
\hline \multicolumn{2}{|l|}{ Planning to have more children } & At this clinic (ref) & 1.00 \\
\hline No (ref) & 1.00 & Not at this clinic & $1.28 \dagger$ \\
\hline Yes & 0.98 & & \\
\hline
\end{tabular}

and 28 gave no response. No clients spontaneously mentioned being told there was a two-week grace period if they could not make their scheduled reinjection date.

- Bivariate analyses. In unadjusted logistic regression analyses among all continuing clients, having ever been late for a previous injection appointment, having been sent away from a clinic without receiving an alternative contraceptive method or having been sent away from a clinic without receiving an injection were associated with greater odds of being late for the reinjection (odds ratios, 1.9-4.0; Table 3). In addition, clients who reported that their partner would have no opinion about their injectable use were more likely to have been late for their reinjection appointment than those who thought their partner would approve of their use of the method (1.7).

A separate analysis was conducted to determine which factors were associated with the likelihood of receiving a reinjection among continuing clients in the Eastern Cape who had returned to the clinic during the grace period (Table 4); the analysis included all the variables previously used in the analysis of client lateness. Clients aged 30 or older were more likely than those aged 20-29 to have received a reinjection (odds ratios, 2.7-8.1), whereas those with a partner who did not know about their method use were less likely than those with a partner who did know to receive a reinjection (0.4). Clients who had ever been pregnant and those who said they would feel happy if they became pregnant in the next six months had elevated odds of receiving a reinjection (2.9 and 4.1, respectively). All but one of the service experience and quality of care variables were significant or marginally significant. Clients who had ever been late for a scheduled reinjection and those who had ever been told to return to a clinic during menses had increased odds of receiving a reinjection (2.1-2.5); those who had ever been sent away from a clinic without receiving an injection or another method had decreased odds of 
reinjection (0.3 and 0.6, respectively). Clients' likelihood of receiving a reinjection increased with the amount of time it took them to get to the clinic (1.02). Finally, clients who missed school or work to go to the clinic were more likely than those who did not to receive a reinjection (2.5).

\section{DISCUSSION}

In our sample of South African injectable users, a substantial proportion of those who intended to continue using the method arrived late for their scheduled reinjections. More than a third of clients in the Eastern Cape who arrived late, but within the two-week grace period, were denied reinjections by providers. If providers are unaware of the grace period, clients may be at risk of unintentional and unnecessary discontinuation of injectable use, which could lead to unintentional pregnancy.

Other studies in South Africa have documented temporary discontinuation (also called nonuse segments) among injectable users, but assumed it to be a conscious decision made by women-without any mention of possible provider- or service-related influences. ${ }^{14,15}$ In one study, clients who returned more than 14 days past their scheduled reinjection were called defaulters and were denied the injectable, even if they wanted to continue use. ${ }^{15}$ Limited attention, however, has been paid to late clients' contribution to high injectable discontinuation rates. One author, however, suggests that discontinuation rates for DMPA are inflated, because the criteria for discontinuation and poor adherence (i.e., lateness) are the same. ${ }^{16}$ Addressing the unintentional discontinuation of clients who did not purposefully take a break or delay their return date, but rather were late for a variety of reasons, is important for ensuring contraceptive coverage for continuing injectable clients who want to avoid unintended pregnancy.

We found few characteristics significantly associated with clients' being late for a reinjection. Although women gave various reasons for being late, some clients' lateness might be explained by misinformation regarding how long it takes to return to fertility after receiving an injection. Clients may believe that the injection works longer than 2-3 months, and thus they are not at risk of pregnancy if they receive a late reinjection.

Providers in the Western Cape appear to be following the South African guidelines, which state "if the possibility of pregnancy cannot be excluded...and [the client] is unable to use condoms or abstain, the injection may be given on the understanding that it will not abort or harm an existing pregnancy." 13 On the other hand, providers in the Eastern Cape seem to be acting more conservatively, by not giving reinjections to women returning beyond the grace period. Unfortunately, they also seem to be selectively giving reinjections to certain women who return during the grace period, while denying others: For example, younger women not wanting to become pregnant in the next six months had increased odds of being denied a reinjection. Although some clients in the Eastern Cape who were denied a reinjection received an alternate contraceptive method such as condoms
TABLE 4. Unadjusted odds ratios from logistic regression analysis examining the likelihood that Eastern Cape continuing clients who returned late, but within the two-week grace period, received a reinjection

\begin{tabular}{|c|c|}
\hline Characteristic & Odds ratio \\
\hline \multicolumn{2}{|l|}{ Age } \\
\hline $15-19$ & 0.60 \\
\hline $20-29$ (ref) & 1.00 \\
\hline $30-39$ & $2.72^{*}$ \\
\hline$\geq 40$ & $8.08+$ \\
\hline \multicolumn{2}{|c|}{ Partner knows client is using this method } \\
\hline Yes (ref) & 1.00 \\
\hline No & $0.41^{* * *}$ \\
\hline \multicolumn{2}{|c|}{ Partner approves client's injectable use } \\
\hline Yes (ref) & 1.00 \\
\hline No & $0.37^{* *}$ \\
\hline No opinion & 0.62 \\
\hline \multicolumn{2}{|l|}{ Ever been pregnant } \\
\hline No (ref) & 1.00 \\
\hline Yes & $2.86^{*}$ \\
\hline \multicolumn{2}{|c|}{ Client happy if pregnant in next 6 mos. } \\
\hline No (ref) & 1.00 \\
\hline Yes & $4.10^{* *}$ \\
\hline \multicolumn{2}{|l|}{ Ever late for scheduled reinjection } \\
\hline No (ref) & 1.00 \\
\hline Yes & $2.49 * *$ \\
\hline \multicolumn{2}{|c|}{ Ever sent away from clinic without any method } \\
\hline No (ref) & 1.00 \\
\hline Yes & $0.55^{* *}$ \\
\hline \multicolumn{2}{|c|}{ Ever sent away from clinic without injection } \\
\hline No (ref) & 1.00 \\
\hline Yes & $0.34^{*}$ \\
\hline \multicolumn{2}{|c|}{ Ever told to return during menses (family planning visit) } \\
\hline No (ref) & 1.00 \\
\hline Yes & $2.12^{* *}$ \\
\hline \multicolumn{2}{|c|}{ Ever told to return during menses (injection visit) } \\
\hline No (ref) & 1.00 \\
\hline Yes & $2.23+$ \\
\hline \multicolumn{2}{|c|}{$\begin{array}{l}\text { Perceived timing of pregnancy risk after missing } \\
\text { scheduled reinjection }\end{array}$} \\
\hline$\leq 2$ wks (ref) & 1.00 \\
\hline$>2$ wks/otherł & $1.76+$ \\
\hline \multicolumn{2}{|l|}{ Transportation to clinic } \\
\hline Other (ref) & 1.00 \\
\hline Walked & 0.86 \\
\hline No. of minutes to clinic (mean) & $1.02^{* * *}$ \\
\hline \multicolumn{2}{|c|}{ Missed school or work to visit clinic today } \\
\hline No (ref) & 1.00 \\
\hline Yes & $2.48^{*}$ \\
\hline
\end{tabular}

${ }^{*} p<.05 .{ }^{* *} p<.01 .{ }^{* * *} p<.001 .+p<.10$. OOther includes when injection wears off, depends how long using injectable, when period returns and do not know. Notes: ref=reference group. Includes all variables from Table 3.

or the pill, the majority did not. It is unclear why some providers refused to give a reinjection but would give oral contraceptives, given that pregnancy should be ruled out prior to initiation of both methods.

The best practices standard of care for family planning according to South African national guidelines is to offer pregnancy tests to clients who are more than two weeks late for their reinjections; however, some providers may be reluctant to administer pregnancy tests for family planning clients-perhaps saving them for antenatal care clients, instead-and some clients may not be able to afford tests from private pharmacies. ${ }^{17}$ In our study, pregnancy tests were rarely used to rule out pregnancy for clients seeking injectable contraceptive services. In the Eastern Cape, a large proportion of women who did not receive a reinjection were told to come back during menses to rule out pregnancy. 
This practice is particularly problematic for continuing injectable users, because use of an injectable may significantly delay their return to regular menses.

\section{Program Implications}

A broad service delivery intervention with providers, may be more effective than a client-targeted intervention at addressing how to prevent and manage late clients. Good provider management can be instrumental in reducing unintentional discontinuation of the injectable. There is already evidence that enhanced client counseling can reduce intentional discontinuation related to side effects. ${ }^{18,19}$

We suggest several strategies for addressing the issues of client lateness and reinjections. First, providers should counsel clients to arrive on time for their reinjections and that the risk of pregnancy increases if they are more than two weeks late for reinjection. Also, providers should give information about the acceptable window for reinjection, so that women who have conflicts with their scheduled appointment have some flexibility and are not afraid to seek services if late. Second, providers should know that clients who present at clinics late but within the two-week grace period are eligible for reinjection without a pregnancy test. Providers who are not knowledgeable about this grace period should receive contraceptive updates and refresher training on the South Africa National Contraception Service Delivery Guidelines. However, the fact that providers in the Western Cape gave reinjections to a greater proportion of their late clients than did their counterparts in the Eastern Cape does not necessarily mean that they are more aware of the grace period. It could be that providers in the Western Cape are less concerned about reinjection during a possible pregnancy or think the risk of a continuing client being pregnant is negligible compared with the benefits of contraceptive coverage.

For clients arriving more than two weeks past their scheduled reinjection date, there must be options for maintaining contraceptive coverage. Increased testing to rule out pregnancy and allow reinjection is the ideal; however, if the unavailability and cost restraints of pregnancy tests are common problems, as they seem to be in most parts of SubSaharan Africa, then the pregnancy checklist can be used to rule out pregnancy. ${ }^{20}$ Some $22-36 \%$ of our sample had not had sex in more than a month, and $32 \%$ had used a condom at last sex. If pregnancy cannot be ruled out by a test or the checklist, then providers could offer condoms to clients who indicate that condom use within their relationships is feasible, to be used until their next menses; however, many women in low-resource settings have difficulty negotiating condom use due to widely recognized gender and power dynamics. ${ }^{21-24}$

\section{Limitations}

This study had several limitations. The cross-sectional design relied on self-reports from about a quarter of respondents regarding dates for last reinjection, which were used for our primary outcome of client lateness. We were able to interview only clients who returned to the clinic. Thus, we missed those who never returned to the clinic and those who went to a different clinic. We were not able to ascertain the proportion of all injectable clients who purposely discontinued and, therefore, did not come to the clinic at all; it might have been useful to know more about women who chose to discontinue the injectable or switched methods, and whether lateness and barriers to receiving a reinjection contributed to their discontinuation of the injectable. Furthermore, we were not able to include length of current injectable use as a variable in our analyses of factors associated with lateness. As amenorrhea increases in long-term use, clients may perceive not having a menstrual cycle as a sign of their inability to get pregnant, which may make them more likely to be late.

\section{Conclusions}

Despite its limitations, the study was able to document how common lateness is in both rural and urban settings in South Africa. It is likely that other countries with limited access to pregnancy tests face similar issues regarding how to manage late injectable clients. Therefore, our results may be useful in other Sub-Saharan African countries that have high rates of injectable discontinuation and have general access barriers to family planning services.

Future research needs to be cognizant of how timeliness may contribute to high rates of injectable discontinuation. Being denied continued use of a preferred method is different from intentional discontinuation. Future research needs to examine whether lateness and differential reinjections are a problem in other countries. Also, interventions need to be developed to assist providers in their management of injectable clients who arrive both within and beyond the acceptable reinjection window. Unless pregnancy can be ruled out, injectable clients who arrive past the grace period have only condoms and abstinence as contraceptive options until their return to menses; research is needed on how to help these women bridge the gap until they can use more effective methods again.

In addition, we need more clarity and standardization of injectable guidelines. For example, WHO guidelines for DMPA and NET-EN are written in terms of months, whereas many countries' guidelines, including South Africa's, are written in terms of weeks. The injection intervals for both DMPA and NET-EN need to be very clearly stated to avoid provider confusion about whether three months means 12 or 13 weeks of contraceptive coverage.

We need to improve counseling for all clients about the timing of reinjection (risk of pregnancy beyond the grace period, but also the window for reinjection if they cannot make their scheduled date). In addition, we need to improve provider management of continuing injectable users, so that those who arrive within the grace period are not denied a reinjection and those who arrive after the grace period are given more appropriate contraceptive bridging strategies until their next injection. The proportion of women using injectable contraceptives is growing, partic- 
ularly in Sub-Saharan Africa, and these methods are an important part of the method mix; however, if continuation rates are poor, injectables cannot fulfill their potential as an effective method of contraception for women.

\section{REFERENCES}

1. Tolley E et al., The impact of menstrual side effects on contraceptive discontinuation: findings from a longitudinal study in Cairo, Egypt, International Family Planning Perspectives, 2005, 31(1):15-23.

2. Hubacher D et al., Factors affecting continuation rates of DMPA, Contraception, 1999, 60(6):345-351.

3. Paul C, Skegg DCG and Williams S, Depot medroxyprogesterone acetate: patterns of use and reasons for discontinuation, Contraception, 1997, 56(4):209-214.

4. Westfall JM, Main DS and Barnard L, Continuation rates among injectable contraceptive users, Family Planning Perspectives, 1996, 28(6):275-277.

5. World Health Organization (WHO), Selected Practice Recommendations for Contraceptive Use, Geneva: WHO, 2004.

6. WHO, Medical Eligibility Criteria for Contraceptive Use, third ed., Geneva: WHO, 2004.

7. Stanback J et al., Menstrual requirements: a significant barrier to contraceptive access in developing countries, Studies in Family Planning, 1997, 28(3):245-250.

8. Hatcher RA et al., The Essentials of Contraceptive Technology, Baltimore, MD, USA: Johns Hopkins University School of Public Health, Population Information Program, 1997.

9. Medical Research Council, Department of Health of South Africa and Macro International, South Africa Demographic and Health Survey 1998, Pretoria, South Africa: Department of Health, 2001.

10. Magwaza S and Cooper D, An Evaluation of the Community Based Distribution of Contraceptives Programme in Khayelitsha, Cape Town: Qualitative Research-An Operational Report, Cape Town, South Africa: University of Cape Town, 1999

11. Cooper D and Marks A, An Evaluation of the Community Based Distribution of Contraceptives Programme in Khayelitsha, Cape Town: Follow Up Survey, Cape Town, South Africa: University of Cape Town, 1999.

12. Department of Health of South Africa, National Contraception Policy Guidelines: Within a Reproductive Health Framework, Pretoria, South Africa: Department of Health, 2003.

13. Department of Health of South Africa, National Contraception Service Delivery Guidelines: Within a Reproductive Health Framework, Pretoria, South Africa: Department of Health, 2003.

14. Beksinska ME et al., Compliance and use behavior, an issue in injectable as well as oral contraceptive use? a study of injectable and oral contraceptive use in Johannesburg, British Journal of Family Planning, 1998, 24(1):21-23.

15. Beksinska ME, Rees HV and Smit F, Temporary discontinuation: a compliance issue in injectable users, Contraception, 2001, 64(5):309-313.

16. Potter LS, Why must one 'restart' a method that is still working? A case for redefining injectable discontinuation, Family Planning Perspectives, 1999, 31(2):98-100.

17. Morroni $\mathrm{C}$ and Moodley J, The role of urine pregnancy testing in facilitating access to antenatal care and abortion services in South Africa: a cross-sectional study, BMC Pregnancy and Childbirth, 2006, Vol. 6, No. 26.

18. Canto De Cetina TE, Canto P and Luna MO, Effect of counseling to improve compliance in Mexican women receiving depot-medroxyprogesterone acetate, Contraception, 2001, 63(3):143-146.

19. Lei ZW et al., Effect of pretreatment counseling on discontinuation rates in Chinese women given depot-medroxyprogesterone acetate for contraception, Contraception, 1996, 53(6):357-361.

20. StanbackJ et al., Checklist for ruling out pregnancy among family planning clients in primary care, Lancet, 1999, 354(9178):566.
21. Jewkes RK, Levin JB and Penn-Kekana LA, Gender inequalities, intimate partner violence and HIV preventive practices: findings of a South African cross-sectional study, Social Science \& Medicine, 2003, 56(1):125-134

22. Maharaj P, Obstacles to negotiating dual protection: perspectives of men and women, African Journal of Reproductive Health, 2001, 5(3):150-161.

23. Harrison A, Xaba N and Kunene P, Understanding safe sex: gender narratives of HIV and pregnancy prevention by rural South African school-going youth, Reproductive Health Matters, 2001, 9(17):63-71.

24. Smit JA et al., Where is the condom? Contraceptive practice in a rural district of South Africa, African Journal of Reproductive Health, 2002, 6(2):71-78.

\section{RESUMEN}

Contexto: Los estudios realizados para examinar la continuación del uso del método de los anticonceptivos hormonales inyectables han concentrado la atención en la discontinuación intencional de las clientas de este método. No obstante, se ha prestado poca atención a la discontinuación no intencional que ocurre debido a la forma que los proveedores atienden a sus clientes que desearían continuar el uso de este método pero que al llegar tarde a su cita de revacunación.

Métodos: Se realizó una encuesta transversal a 1.042 mujeres que utilizaban inyectables y que asistían a 10 clínicas públicas ubicadas en las provincias del Cabo Occidental y Oriental de Sudáfrica. Se utilizaron análisis de regresión logística con dos variables para identificar las relaciones que habia entre variables específicas y la probabilidad de recibir una revacunación, entre las clientas que regresaban a las clínicas en forma tardía pero dentro de un período de gracia de dos semanas para recibir la revacunación.

Resultados: De las 626 clientas que continuaban utilizando la vacunación de la zona del Cabo Occidental, el 29\% llegó a su cita de revacunación hasta dos semanas tarde y el 25\% llegó entre 2 y 12 semanas tarde; estos porcentajes entre las 416 clientas de la zona del Cabo Oriental fueron del $42 \%$ y 16\%, respectivamente. Solo el 1\% de las clientas que continuaron con este método de la zona del Cabo Occidental y que llegaron dentro del período de gracia de dos semanas no recibieron la revacunación; no obstante, el 36\% de las clientas en similar situación del Cabo Oriental no recibieron la revacunación. Entre el grupo de clientas del Cabo Oriental que no recibieron una revacunación, el 64\% no recibió ningún otro método. En los análisis de bivariables fueron pocas las variables significativas; no obstante, ciertas características estuvieron relacionadas con haber recibido las revacunaciones entre las clientas del Cabo Oriental que llegaron tarde a su cita.

Conclusiones: En este entorno es común que las clientas lleguen tarde a su cita de revacunación. Los proveedores deben cumplir con los protocolos correspondientes al período de gracia de la revacunación y deberán disponer de un plan de cobertura de anticonceptivos para las clientas que llegan tarde después de concluir el período de gracia, con el fin de reducir el riesgo de que haya una discontinuación no intencional del uso de inyectables $y$ de que sus clientas tengan embarazos no deseados.

\section{RÉSUMÉ}

Contexte: La recherche relative à la poursuite de la contracep- 
tion hormonale injectable s'est concentrée sur l'interruption intentionnelle de la pratique des clientes. Peu d'attention a cependant été accordée à l'interruption non intentionnelle imputable à la gestion par les prestataires des clientes qui aimeraient continuer la méthode mais qui se présentent en retard pour leurs réinjections planifiées.

Méthodes: Une enquête transversale a été menée sur 1.042 clientes poursuivant le contraceptif injectable dans 10 cliniques publiques des provinces sud-africaines de Cap Ouest et Cap Est. Des analyses de régression logistiques bivariées ont servi à identifier les associations entre certaines variables spécifiques et la probabilité de recevoir une réinjection, parmi les clientes revenues dans les cliniques en retard mais dans le délai de grâce de deux semaines imparti.

Résultats: Des 626 clientes poursuivant la méthode à Cap Ouest, 29\% sont revenues dans un délai de deux semaines après leur visite de réinjection planifiée et $25 \%$ avaient un retard de 2 à 12 semaines; parmi les 416 clientes de Cap Est, ces proportions étaient de $42 \%$ et $16 \%$, respectivement. Un pour cent seulement des clientes de Cap Ouest revenues pendant les deux semaines de grâce n'a pas obtenu leur réinjection; à Cap Est, toutefois, ce même pourcentage s'élevait à 36\%. Parmi les clientes tardives de Cap Est qui n'ont pas reçu de réinjection, 64\% n'ont pas obtenu d'autre méthode non plus. Peu de variables se sont avérées significatives dans les analyses bivariées. Certaines caractéristiques sont cependant associées à l'obtention de réinjections parmi les clientes tardives de Cap Est.

Conclusions: Le retour tardif des clientes devant recevoir une réinjection est courant dans le contexte examiné. Les prestataires devraient adhérer aux protocoles du délai de grâce et proposer un plan de couverture contraceptive aux clientes qui dépasseraient ce délai afin de réduire leur risque d'interruption non intentionnelle et de grossesse non planifiée.

\section{Acknowledgments}

The authors gratefully acknowledge the contributions of Di Cooper, Theresa Hatzell Hoke, Marlina Nasution and Beth Raymond in the areas of study design, instrument development and manuscript review. The authors also thank the local advisory committee for this study, which included provincial health authority representatives Marie Adamo in the Western Cape, Nomvume Ntshanga in the Eastern Cape and Margaret Moss. The U.S. Agency for International Development provided financial support for this project under cooperative agreement CCP-A-00-95-00022-02.

Author contact: jbaumgartner@fhi.org 